\title{
Reduction in Dental Hypersensitivity with Nano-Hydroxyapatite, Potassium Nitrate, Sodium Monoflurophosphate and Antioxidants
}

\author{
Samuel B. Low ${ }^{1,4, *}$, Edward P. Allen ${ }^{2}$ and Elias D. Kontogiorgos ${ }^{3}$ \\ ${ }^{I}$ Department of Periodontics, University of Florida College of Dentistry, University of Florida, Gainesville, Florida \\ 32610, USA; ${ }^{2}$ Department of Periodontics, Texas A\&M University, Baylor College of Dentistry; Dallas, Texas 75246 , \\ USA; ${ }^{3}$ Department of Restorative Sciences, Texas A\&M, Baylor University, College of Dentistry, Dallas, Texas 75246, \\ USA; ${ }^{4}$ PerioSciences LLC., Dallas, Texas
}

\begin{abstract}
Objective: This clinical study aimed to evaluate effectiveness of a commercially available toothpaste containing potassium nitrate, sodium monoflurophosphate, and nano-hydroxyapatite as well as antioxidants phloretin, ferulic acid and silymarin in reducing dental hypersensitivity in adults. Materials and methods: The clinical trial enrolled patients with a history of dentin hypersensitivity. A test toothpaste was introduced into the daily routine, which included initial instruction on usage. Patients completed a five-question visual analog scale (VAS) at the inception/baseline, after two days and after two weeks of using the toothpaste to determine their level of tooth sensitivity at baseline with the use of the toothpaste over time. Results: Patients that had significant sensitivity at baseline had a range of 52\% to $76 \%$ improvement after 48 hours and a range of $70 \%$ to $84 \%$ improvement after two weeks. Conclusion: A toothpaste containing potassium nitrate, sodium monoflurophosphate, and nano-hydroxyapatite plus antioxidants phloretin, ferulic acid and silymarin applied daily significantly decreased tooth pain of dentin hypersensitivity within a two-day and two-week time period. Clinical Significance: Based on the clinical study results, a daily application of a toothpaste containing potassium nitrate, sodium monofluorophosphate, and nano-hydroxyapatite plus antioxidants phloretin, ferulic acid and silymarin can significantly and quickly reduce tooth pain of dentin hypersensitivity.
\end{abstract}

Keywords: Antioxidants, dentin hypersensitivity, hydroxyapatite, polyphenol.

\section{INTRODUCTION}

Dentin hypersensitivity (DH) is defined as a short, sharp pain caused by cold and heat, air, touch, or chemical or osmotic stimuli, e.g., sweets. It is distinguished from dental pain caused by a cracked or split tooth, untreated caries, or other oral defect or disease. It affects as many as 85 percent of the population [1].

There are three major theories regarding the mechanisms of dentin hypersensitivity. The direct innervation theory proposes that nerve endings extend through the pulp and dentin up to the dentino-enamel junction [2]. The odontoblast receptor theory suggests that odontoblasts are receptors, relaying a signal to a nerve terminal [3]. Neither the direct innervation theory nor the odontoblast receptor theory is currently favored.

Most scientists and practitioners accept the hydrodynamic theory as the mechanism behind DH. First proposed by Brännström, the theory holds that dentin hypersensitivity is the result of movement of fluid within the dentinal tubules, which are open to the dentin surface and patent to the pulp. $[4,5]$.

*Address correspondence to this author at the Department of Periodontics, University of Florida College of Dentistry, University of Florida, Gainesville, Florida 32610, USA; Tel: 352 538-9654;

E-mail: slow@dental.ufl.edu

\#Supported in part by Perio Sciences LLC
Treatments for $\mathrm{DH}$ are classified by their administration as in-office or at-home remedies. In-office treatments include those that use a setting reaction, such as glass ionomer cement or composites, or those that do not use a setting reaction, such as varnishes and oxalates. At-home remedies include tooth powders and pastes, mouthwashes and chewing gums.3 Often, a dental professional's first recommendation for treatment is an at-home desensitizing toothpaste because it is simple to use, inexpensive and readily available.

DH treatments, including at-home and in-office, are also classified by their mechanism of action, either disturbing the transmission of nerve impulses or occluding the dentinal tubules [6].

Potassium is the primary agent for at-home desensitizing toothpastes that disturb the transmission of nerve endings. Potassium salts, including potassium nitrate, potassium chloride or potassium citrate act by diffusion along the dentinal tubules to depolarize the nerve cells so they become unresponsive to excitatory stimuli. The effect of the potassium nitrate is cumulative and it may take several weeks for patients to feel any pain reduction [7].

The second category of desensitizing toothpaste is based on occluding the dentinal tubules to block the hydrodynamic mechanism and pain stimulation. Depositing a thin coating, or "artificial smear layer," on the exposed dentin, can bring about the occlusion. Also, remineralizing the exposed dentin surface with deposits or precipitation of fine particles can work to occlude the dentinal tubules [7]. 
Since the mid-twentieth century, the principal agent for re-mineralization has been fluoride. Fluoride has been added to municipal water systems with great success. Manufacturers have formulated toothpastes with sodium monofluorophosphate or stannous fluoride. Although fluoride compounds are primarily used for preventing or treating dental caries, their remineralization properties have placed them in the forefront of treating $\mathrm{DH}$ as well.

In recent years, researchers have investigated the effectiveness of hydroxyapatite for remineralizing tooth enamel as a remedy for dental caries. A 2009 study concluded that nano-hydroxyapatite had the potential to remineralize initial enamel lesions. A concentration of 10\% nano-hydroxyapatite may be optimal for remineralization of early enamel caries [8]. An in vitro study in 2011 concluded that toothpastes containing nano-hydroxyapatite revealed higher remineralizing effects when compared to amine fluoride toothpastes [9]. Li et al. affirmed that nano-hydroxyapatite, with particles of $20 \mathrm{~nm}$, shares characteristics with the natural building blocks of enamel so that it may be used as an effective repair material and anti-caries agent [10].

In view of its remineralization properties, nanohydroxyapatite, like fluoride, has great promise for treating DH as well as dental caries. Browning et al. showed that a paste containing nano-hydroxyapatite crystal can effectively reduce the duration of tooth sensitivity for patients who use a tooth whitener without a desensitizing agent [11].

The aim of the present clinical study was to investigate the effectiveness of a commercially available toothpaste containing nano-hydroxyapatite along with potassium nitrate and sodium monoflurophosphate in reducing dental hypersensitivity in adults. The toothpaste also contains antioxidants phloretin, ferulic acid and silymarin.

\section{METHODS AND MATERIALS}

Sixty adult patients with dentin hypersensitivity were enrolled in a clinical trial to measure the effect of a toothpaste containing potassium nitrate, sodium monofluorophosphate, and nano-hydroxyapatite. Patients signed an information/informed consent document before admission as a subject into the trial. A fully executed copy of the consent document was provided to the patient and the original consent kept by the investigator. The study was performed in compliance with guidelines established by the World Medical Association Declaration of Helsinki Ethical Principles for Medical Research Involving Human Subjects.

Patients that demonstrated dentinal hypersensitivity were recruited from the private dental practice sector of twenty practices of general dentistry. Exclusion criteria included sensitivity due to (i) decay, (ii) infections of the tooth nerve, (iii) cracked teeth, (iv) fractured fillings or crowns, or (v) recent crown or filling sensitivity. The study participants were adults ranging in age from 18 to 75 years. Of the 60 subjects, 47 were female, 13 were male. Patients were in good health. Each participant was given the test toothpaste to use at home and was instructed to first apply the toothpaste to the sensitive area on the teeth using toothbrush, finger or cotton swab. Next patients were to brush all other areas of the mouth with the toothpaste as with their normal oral hygiene routine. Finally, they were to brush the sensitive area.
Patients were instructed to use the toothpaste at least once a day and to discontinue any other toothpaste during the trial.

The patients completed a baseline visual analog scale (VAS) survey in the respective dental office. Fig. (1). They were given copies of the survey to complete at home after two days of using the toothpaste and again after two weeks of daily usage. The surveys were mailed back to the investigator using self-addressed, postage-paid envelopes.

\section{Baseline}

Directions: Please mark to indicate your level of pain from sensitive teeth. Please place a vertical line on the scale that best represents your current state. Thank you for your participation.

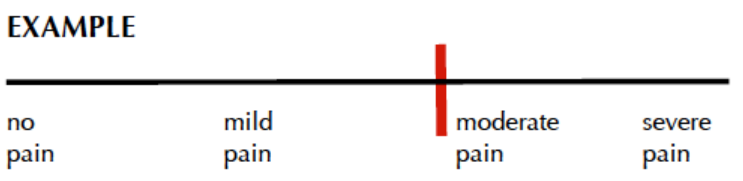

1. Degree of pain.

\begin{tabular}{llll}
\hline no & mild & moderate & severe \\
pain & pain & pain & pain
\end{tabular}

2. Duration of pain.

\begin{tabular}{|c|c|c|c|}
\hline $\begin{array}{l}\text { no } \\
\text { pain }\end{array}$ & temporary & quick & lingering \\
\hline
\end{tabular}

3. Intensity of pain.

\begin{tabular}{lllll}
\hline no \\
pain
\end{tabular}

4. Tolerability of pain.

no tolerable uncomfortable unnerving unbearable
pain

5.Description of pain.

$\begin{array}{lll}\text { no twinge } & \text { ache throbbing shooting } \\ \text { pain } & \end{array}$

Fig. (1). Visual analog scale.

The survey contained five questions, rated on a 10-point scale, asking (i) degree of pain, (ii) duration of pain, (iii) intensity of pain, (iv) tolerability of pain, and (v) description of pain.

Statistical analysis was conducted using SPSS v.18 (SPSS Inc., Chicago, IL). The collected data were subjected to repeated measures multivariate analysis of variance (MANOVA, $\mathrm{P} \leq .05$ ) to determine significant improvement in pain relief among the patients over time. Time was used as the within-subject factor and gender as the between-subject factor. Post-hoc statistical comparisons were made at 95\% con- 
fidence interval of the mean, adjusting for multiple comparisons (Sidak's adjustment). Further, the number of patients that improved by at least $10 \%$ over time was calculated. Also, the number of patients that scored five or higher on the survey at baseline and improved at least $10 \%$ over time was calculated. The score of 5 or higher at baseline was considered to be moderate to severe hypersensitivity.

\section{RESULTS}

From the 60 patients enrolled in the study, all completed the five-point questionnaire at baseline, 59 at the two-day point and 50 at the two-week time point. There were no adverse events reported by the patients or denoted clinically by the dentists. Table 1 displays the patient demographics included in the study with the majority of the patients $(53.3 \%)$ reporting hypersensitivity due to tooth root exposure.

Table 1. Patient data included in this study according to gender, age and dental sensitivity.

\begin{tabular}{|c|c|c|}
\hline Sample Size (N) & 60 patients & $100.0 \%$ \\
\hline Gender & 47 females & $78.3 \%$ \\
\hline AGE $18-25$ & 7 patients & $12.1 \%$ \\
\hline AGE $26-35$ & 7 patients & $12.1 \%$ \\
\hline AGE $36-45$ & 11 patients & $19.0 \%$ \\
\hline AGE $46-55$ & 11 patients & $19.0 \%$ \\
\hline AGE $56-65$ & 10 patients & $17.2 \%$ \\
\hline AGE $66-75$ & 11 patients & $19.0 \%$ \\
\hline AGE $75-82$ & 1 patients & $1.7 \%$ \\
\hline $\begin{array}{l}\text { SENSITIVE DUE TO TOOTH } \\
\text { EXPOSURE }\end{array}$ & 32 patients & $53.3 \%$ \\
\hline $\begin{array}{c}\text { SENSITIVE DUE TO TEETH } \\
\text { WHITENING }\end{array}$ & 9 patients & $15.0 \%$ \\
\hline $\begin{array}{l}\text { SENSTIVITY DUE TO } \\
\text { CHEMO/RADIATION }\end{array}$ & 0 patients & $0.0 \%$ \\
\hline SENSITIVITY DUE TO OTHER & 10 patients & $16.7 \%$ \\
\hline $\begin{array}{l}\text { SENSITIVITY DUE TO } \\
\text { UNKNOWN }\end{array}$ & 9 patients & $15.0 \%$ \\
\hline
\end{tabular}

The repeated measures MANOVA revealed significant differences in pain relief according to time $(\mathrm{P} \leq .001)$ as shown in Tables $\mathbf{2}$ and 3. Overall there was a significant decrease in perception of pain at the two-day and the two-week point as shown in Table 4.

The number of patients that improved by at least $10 \%$ according to each question is shown in Table 5. Data from all the questions suggest that a range of $42 \%$ to $65 \%$ of patients experienced pain relief at the two-day point and $60 \%$ to $78 \%$ of the patients at the two-week point.

The number of patients that scored five or higher on the survey at baseline according to question is shown in Table 6. For all questions, a range of $52 \%$ to $76 \%$ of patients experi- enced at least $10 \%$ of pain relief at the two-day point and $70 \%$ to $84 \%$ of the patients at the two-week point.

\section{DISCUSSION}

Potassium nitrate and sodium monofluorophosphate have been included in the ingredients of commercially available toothpaste as well as desensitizing toothpaste for decades. Their efficacy in decreasing sensitivity has been welldocumented. In a review of hypersensitivity, Walsh stated that fluoride works primarily via topical mechanisms, which include (i) inhibition of demineralization at the crystal surfaces inside the tooth, (ii) enhancement of remineralization at the crystal surfaces (giving an acid resistant surface to the reformed crystals), and, at higher concentrations, (iii) inhibition of bacterial enzymes. Low levels of fluoride in saliva and plaque help prevent and reverse caries by inhibiting demineralization and enhancing remineralization [12].

Regarding potassium nitrate, according to Pashley, numerous clinical studies have indicated that [KNO3] is moderately effective in reducing clinical dentin hypersensitivity. KNO3 desensitizes, not by occluding tubules, but by reducing the sensitivity of the mechanoreceptor nerves to the fluid shifts produced by normally painful stimuli. In this case, the stimuli would still cause hydrodynamic fluid shifts, but the nerves would not fire because they would be inexcitable [13]. Pointing to work by Nahri and Haegerstam [14] Pashley also notes that there is experimental, scientific evidence to support the clinical observations by Hodosh and by Tarbet et al. [15-17] that KNO3 decreases dentin sensitivity.

As potassium nitrate works on the nerve receptors, sodium monofluorophosphate and nano-hydroxyapatite have a different mechanism, i.e., occluding the dentinal tubules and limiting the movement of the dentinal fluid. Although fluoride compounds are well-known for remineralizing enamel, nano-hydroxyapatite is a relative newcomer in the industry.

Hydroxyapatite, a compound of calcium and phosphate, is a natural substance that makes up about 75 percent of the weight of dentin. It has excellent biological properties including non-toxic and non-inflammatory; and it has bioresorption properties under physiological conditions. Roveri affirmed the possibility of enamel remineralization by forming a surface apatite coating to cover the enamel structure. [18].

Most of the experimentation on hydroxyapatite to date has been with studies on remineralizing enamel and on a lesser scale, dentin. Nano-hydroxyapatite crystals small enough to mimic the size of natural dentinal hydroxyapatite $(20 \mathrm{~nm})$ have been used to repair micrometer-sized tooth surface defects in vitro. The nano-crystals have been used in tooth pastes and mouth rinses to promote the repair of demineralized enamel or dentine surfaces [19]. Some prophylactic products have been shown in vitro to fill micro defects at the etched enamel surface in as little as a ten-minute application onto enamel or dentine surfaces [18].

Studies into the efficacy of nano-hydroxyapatite on dentin, to address $\mathrm{DH}$, are beginning to accumulate. Shetty found that both a $25 \%$ concentration of hydroxyapatite in a liquid slurry as well as a $100 \%$ concentration in a dry sol version provided significant desensitization. However, the 
Table 2. Repeated-measures MANOVA with time as within-subject factor and gender as between-subject factor (P $\leq .05)$ for all questions.

\begin{tabular}{|c|c|c|c|c|}
\hline Source & F Value* & Hypothesis df & Error df & Significance \\
\hline \hline Time & 10.512 & 10.000 & 168.000 & $\mathrm{P} \leq .001$ \\
\hline Time * Gender & 0.660 & 10.000 & 18.000 & $\mathrm{P}=.760$ \\
\hline
\end{tabular}

*F-values are based on Wilk's Lambda statistics.

Table 3. Repeated-measures MANOVA with time as within-subject factor and gender as between-subject factor (P $\leq .05)$ according to each question.

\begin{tabular}{|c|c|c|c|c|c|c|}
\hline Source & Question & Type III Sum of Squares & df & Mean Square & $\mathbf{F}$ & Significance \\
\hline \multirow[t]{3}{*}{ Time } & Q1 & 163.729 & 2 & 81.864 & 54.474 & $\mathrm{P} \leq .001$ \\
\hline & Q3 & 133.560 & 2 & 66.780 & 32.884 & $\mathrm{P} \leq .001$ \\
\hline & Q4 & 98.491 & 2 & 49.245 & 27.137 & $\mathrm{P} \leq .001$ \\
\hline \multirow[t]{4}{*}{ Time*Gender } & Q1 & 3.925 & 2 & 1.963 & 1.306 & $\mathrm{P}=.276$ \\
\hline & Q2 & 2.501 & 2 & 1.250 & 0.792 & $\mathrm{P}=.456$ \\
\hline & Q3 & 1.244 & 2 & 0.622 & 0.306 & $\mathrm{P}=.737$ \\
\hline & Q4 & 1.456 & 2 & 0.728 & 0.401 & $\mathrm{P}=.671$ \\
\hline \multirow{3}{*}{ Error (Time) } & Q3 & 178.707 & 88 & 2.031 & & \\
\hline & Q4 & 159.696 & 88 & 1.815 & & \\
\hline & Q5 & 378.925 & 88 & 4.306 & & \\
\hline
\end{tabular}

Table 4. Post-hoc analysis of the data (mean \pm standard deviation) for every question according to time. Used Sidak's adjustment for multiple comparisons $(\mathrm{P} \leq .05)$.

\begin{tabular}{|c|c|c|c|c|c|}
\hline Time & $\begin{array}{c}\text { Question 1 } \\
\text { Degree of Pain }\end{array}$ & $\begin{array}{c}\text { Question 2 } \\
\text { Duration of Pain }\end{array}$ & $\begin{array}{c}\text { Question 3 } \\
\text { Intensity of Pain }\end{array}$ & $\begin{array}{c}\text { Question 4 } \\
\text { Tolerability of Pain }\end{array}$ & $\begin{array}{c}\text { Question 5 } \\
\text { Description of Pain }\end{array}$ \\
\hline \hline Baseline & $5.7( \pm 1.8)$ & $4.3( \pm 1.8)$ & $5.9( \pm 1.7)$ & $4.6( \pm 2.0)$ & $5.6( \pm 2.6)$ \\
\hline Day 2 & $3.6( \pm 2.2)^{\mathrm{a}}$ & $3.3( \pm 2.1)^{\mathrm{a}}$ & $4.5( \pm 2.1)^{\mathrm{a}}$ & $3.2( \pm 2.3)^{\mathrm{a}}$ & $4.9( \pm 2.8)$ \\
\hline Week 2 & $2.5( \pm 1.9)^{\mathrm{b}, \mathrm{c}}$ & $2.2( \pm 1.8)^{\mathrm{b}, \mathrm{c}}$ & $3.0( \pm 2.1)^{\mathrm{b}, \mathrm{c}}$ & $2.1( \pm 1.8)^{\mathrm{b}, \mathrm{c}}$ & $3.5( \pm 2.8)^{\mathrm{b}, \mathrm{c}}$ \\
\hline
\end{tabular}

a. Indicates statistical difference between Baseline and Day 2

b. Indicates statistical difference between Baseline and Week 2

c. Indicates statistical difference between Day 2 and Week 2

Table 5. Number of patients that showed improvement (\%) by at least $10 \%$ on the VAS according to question.

\begin{tabular}{|c|c|c|c|c|c|c|c|c|c|c|}
\hline \multirow[b]{2}{*}{ Time } & \multicolumn{2}{|c|}{$\begin{array}{c}\text { Question 1 } \\
\text { Degree of Pain }\end{array}$} & \multicolumn{2}{|c|}{$\begin{array}{c}\text { Question 2 } \\
\text { Duration of Pain }\end{array}$} & \multicolumn{2}{|c|}{$\begin{array}{c}\text { Question } 3 \\
\text { Intensity of Pain }\end{array}$} & \multicolumn{2}{|c|}{$\begin{array}{c}\text { Question } 4 \\
\text { Tolerability of Pain }\end{array}$} & \multicolumn{2}{|c|}{$\begin{array}{c}\text { Question } 5 \\
\text { Description of Pain }\end{array}$} \\
\hline & Patients & Improvement(\%)* & Patients & Improvement & Patients & Improvement & Patients & Improvement & Patients & Improvement \\
\hline Day2 & $39(65 \%)$ & $50.3( \pm 26.3)$ & $27(45 \%)$ & $51.6( \pm 28.6)$ & $32(53 \%)$ & $45.0( \pm 28.4)$ & $32(52 \%)$ & $52.5( \pm 28.2)$ & $25(42 \%)$ & $49.9( \pm 30.3)$ \\
\hline Week2 & $47(78 \%)$ & $59.4( \pm 24.9)$ & $41(68 \%)$ & $58.6( \pm 25.3)$ & $43(72 \%)$ & $58.8( \pm 25.3)$ & $44(73 \%)$ & $59.9( \pm 23.9)$ & $36(60 \%)$ & $60.1( \pm 27.4)$ \\
\hline
\end{tabular}

* Improvement (\%) values are presented as Mean $( \pm$ Standard Deviation) 
Table 6. Number of patients that answered $>5$ at Baseline and showed improvement (\%) by at least $10 \%$ on the VAS according to question.

\begin{tabular}{|c|c|c|c|c|c|c|c|c|c|c|}
\hline & \multicolumn{2}{|c|}{$\begin{array}{c}\text { Question 1 } \\
\text { Degree of Pain }\end{array}$} & \multicolumn{2}{c|}{$\begin{array}{c}\text { Question 2 } \\
\text { Duration of Pain }\end{array}$} & \multicolumn{2}{c|}{$\begin{array}{c}\text { Question 3 } \\
\text { Intensity of Pain }\end{array}$} & \multicolumn{2}{c|}{$\begin{array}{c}\text { Question 4 } \\
\text { Tolerability of Pain }\end{array}$} & $\begin{array}{c}\text { Question 5 } \\
\text { Description of Pain }\end{array}$ \\
\hline Time & Patients & Improvement(\%)* & Patients & Improvement & Patients & Improvement & Patients & Improvement & Patients & Improvement \\
\hline \hline Baseline & 38 & - & 19 & - & 46 & - & 29 & - & 30 & - \\
\hline Day2 & $29(76 \%)$ & $51.1( \pm 24.9)$ & $14(74 \%)$ & $43.0( \pm 26.2)$ & $24(52 \%)$ & $46.4( \pm 26.0)$ & $19(66 \%)$ & $51.4( \pm 26.8)$ & $17(57 \%)$ & $49.1( \pm 27.8)$ \\
\hline Week2 & $32(84 \%)$ & $57.9( \pm 24.3)$ & $16(84 \%)$ & $50.6( \pm 19.6)$ & $34(74 \%)$ & $55.4( \pm 25.6)$ & $24(83 \%)$ & $60.3( \pm 25.3)$ & $21(70 \%)$ & $62.2( \pm 28.7)$ \\
\hline
\end{tabular}

*Improvement (\%) values are presented as Mean ( \pm Standard Deviation)

higher concentration probably enhanced better penetration of the particles into the tubules. Most of the patients in the study obtained relief with just one or two applications of hydroxyapatite [20] Shetty also concluded that hydroxyapatite has potential as an effective desensitizing agent, providing quick and sustained relief from symptoms when compared to the other agents, although hypersensitivity symptoms were substantially reduced in all the treatment groups [21].

On top of the effectiveness at remineralization, hydroxyapatite powder has also been shown to be an effective abrasive cleansing agent for dental hygiene [20,22].

Nano-hydroxyapatite is used in several toothpastes available in Europe and Australia, but apparently only rarely in the U.S. This is surprising considering the number of studies that have confirmed its efficacy in remineralizing enamel and dentin. The results of this clinical study suggest that nano-hydroxyapatite may well be a potent ingredient in toothpaste for decreasing $\mathrm{DH}$.

A limitation of the study was the inability to determine which ingredient may have had an effect on the resulting decrease in hypersensitivity. A good example is the role of the antioxidants. It is important to note that antioxidants in this product bear further research on their contributing role. In simple terms, antioxidants are large, complex organic molecules that "donate" electrons, neutralizing the reactivity of unpaired electrons in free radicals or reactive oxygen species (ROS). There are a number of possibilities for investigation concerning the activity of antioxidants in the remineralization process for both fluoride and nano-hydroxyapatite: the anti-inflammatory inhibition of MMPs and the effect of antioxidants on salivary $\mathrm{pH}$.

Researchers have investigated the role of matrix metalloproteinases (MMPs) in dental caries and concluded that MMPs contribute to carious decay through the destruction of the dentin organic matrix following demineralization by bacterial acids [23-25]. Kato et al. found that gels delivering MMP inhibitors chlorhexidine and the polyphenol epigallocatechin gallate (EGCG) were shown to prevent dental erosion in situ. Both chlorhexidine and polyphenols are able to interact with metal ions, which could bind calcium from hydroxyapatite, to deposit particles inside the tubules [26] Although a number of studies have focused on the MMP inhibitors EGCG and chlorhexidine, various polyphenol antioxidants, including flavonoids, have been shown to have MMP inhibition properties [27]. Also, antioxidants are thought to shield the dentition by decreasing the effects of acid erosion, and by replenishing tissue inhibitors of metalloproteinases (TIMPs) in the dentin [28].

Another related possibility for continued research is the effect of supplemental polyphenol antioxidants on the chemical composition of saliva, in particular the $\mathrm{pH}$ levels. Remineralization involves transporting calcium and phosphate to plug the dentinal tubules as well as forming a protective surface layer of salivary glycoprotein with calcium and phosphate. This process is more favorable in alkaline $\mathrm{pH}$, so a slightly alkaline $\mathrm{pH}$ in saliva is helpful for tubule occlusion [7]. Hurlbutt observes that as the $\mathrm{pH}$ drops from bacterial acid by-products, the level of super saturation of the calcium and phosphate also drops and the risk of demineralization increases. While there is no exact $\mathrm{pH}$ at which demineralization begins, a general range of 5.5 to 5.0 is considered critical for tooth mineral to dissolve [29].

The limitation of this study included not incorporating a placebo control group. And while each subject was their own control by demonstrating continued dentin hypersensitivity even with prior use of desensitizing agents, there is a significant possibility that a "placebo effect" could have biased their perception of pain. The majority of subjects demonstrated a significant improvement on all survey questions at 48 hours of using the test toothpaste and even more improvement at the close of the two-week study. Patients that scored greater than 5 on the VAS (moderate to severe hypersensitivity) also demonstrated significant improvement especially at two weeks. The increase in improvement is postulated to be that more dentinal tubules are occluded with the nano-hydroxyapatite particulates over time.

Further research is indicated to better differentiate the role and mechanisms of the different ingredients. Future clinical studies would benefit by using more subjects, by isolating the ingredients, and by incorporating placebo and control groups. In addition, the use of more than one method for assessing pain, e.g., both a visual analog scale (VAS) and a verbal reporting scale (VRS), would be helpful. Further, using more than one stimulus e.g., a combination of thermal, osmotic, chemical or electrical stimuli to assess hypersensitivity could provide a richer basis for analysis [20].

These limitations notwithstanding, this clinical research study affirms the efficacy of the well-known components potassium nitrate and monofluorophosphate at alleviating dentin hypersensitivity. More important, the outstanding results of speed and effectiveness of the commercially avail- 
able toothpaste suggest the contributing activity of the newer nano-hydroxyapatite and of the polyphenol antioxidants.

\section{CONFLICT OF INTEREST}

The authors, Samuel B. Low and Edward P. Allen are consultants for PerioSciences LLC.

\section{ACKNOWLEDGEMENTS}

The authors appreciate Emily Martin for assistance in manuscript preparation and a special thank you to the following participating practitioners: Dr. Robert Hood, Dr. James Goates, Dr. James Carreiro, Dr. Tom Wright, Dr. Ryan Coulon, Dr. Glenda Owen, Dr. Michelle Hedgecock, Dr. David Brinkley, Dr. Hugo Artaza, Dr. Karen Williamson, Dr. Beth Tomlin, Dr. Mark Williamson, Dr. Byron McKnight, Dr. Bradley Peter Boeke.

\section{REFERENCES}

[1] Addy M. Dentine hypersensitivity: new perspectives on an old problem. Int Dental J 2002; 52(5): 367-75.

[2] Irvine JH. Root surface sensitivity: a review of aetiology and management. J N Z Soc Periodontol 1988; 66: 15-8.

[3] Miglani S, Aggarwal V, Ahuja B. Dentine hypersensitivity: recent trends in management. J Conserv Dent 2010; 13(4): 218-24.

[4] Brännström M. Etiology of dentin hypersensitivity. Proc Finn Dent Soc 1992; 88(1): 7-13.

[5] Absi EG, Addy M, Adams D. Dentin hypersensitivity: a study of the patency of dentinal tubules in sensitive and non-sensitive cervical dentine. J Clin Periodontol 1987; 14: 280-4.

[6] Davari AR, Ataei E, Assarzadeh H. Dentin hypersensitivity: etiology, diagnosis and treatment; a literature review. J Dent Shiraz Uni Med Sci 2013; 14(3): 136-45.

[7] Cummins D. Recent advances in dentin hypersensitivity: CLINICALLY proven treatments for instant and lasting sensitivity relief. Am J Dent 2010; 23 (Spe Issue) A: 3A-13A.

[8] Huang SB, Gao SS, Yu HY. Effect of nano-hydroxyapatite concentration on remineralization of initial enamel lesion in vitro. Biomed Mater 2009; 4(3): 034104.

[9] Tschoppe P, Zandim DL, Martus P, Kielbassa AM. Enamel and dentine remineralization by nano-hydroxyapatite toothpastes. J Dent 2011; 39(6): 430-7.

[10] Li L, Pan H, Tao J, et al. Repair of enamel by using hydroxyapatite nanoparticles as the building blocks. J Mater Chem 2008; 18: 407984.
[11] Browning WD, Cho SD, Deschepper EJ. Effect of a nanohydroxyapatite paste on bleaching-related tooth sensitivity. J Esthet Restorat Dent 2012; 24(4): 268-76.

[12] Walsh LJ. Contemporary technologies for remineralization therapies: a review. Int Dent SA 2009; 11(6): 6-16.

[13] Pashley DH. Dentin permeability, dentin sensitivity, and treatment through tubule occlusion. J Endodont 1986; 12(10): 465-74.

[14] Nahri M, Haegerstam G. Intradental nerve activity induced by reduced pressure applied to exposed dentine in the cat. Acta Physiologica 1983; 119: 381-6.

[15] Tarbet WJ, Silverman G, Stolman JM, Fratareangelo PA. An evaluation of two methods for the quantitation of dentinal hypersensitivity. J Am Dental Assoc 1979; 98: 914-8.

[16] Hodosh MA. A superior desensitizer, potassium nitrate. JAm Dental Assoc 1974; 88: 831-3.

[17] Tarbet WJ, Silverman G, Fratareangelo PS, Kauapka JA. Home treatment for dentinal hypersensitity: a comparative study. J Am Dental Assoc 1982; 105: 227-30.

[18] Roveri N, Battistella E, Bianchi CL, et al. Surface enamel remineralization: Biomimetic apatite nanocrystals and fluoride ions different effects. J Nanomaterials 2009; 2009: 9.

[19] Hannig M, Hannig C. Nanomaterials in preventive dentistry. Nat Nanotechnol 2010; 5: 565-9.

[20] Shetty S, Kohad R, Yeltiwar R. Hydroxyapatite as an in-office agent for tooth hypersensitivity: a clinical and scanning electron microscopic study. J Periodontol 2010; 81: 1781-9.

[21] Shetty S, Kohad R, Yeltiwar R, Shetty K. Comparative evaluation of hydroxyapatite, potassium nitrate and sodium monofluorophosphate as in-office desensitizing agents: a double-blinded randomized controlled clinical trial. Oral Hyg Health 2013; 1(1): 104.

[22] Ślósarczyk A, Zofia KK, Stobierska E, Paszkiewicz A. Cracow hydroxyapatite ceramics: a product report. Med Sci Monitor 1998; 4: $172-5$.

[23] Chaussain-Miller C, Fioretti F, Goldberg M, Menashi S. The role of matrix metalloproteinases (MMPs) in human caries. J Dental Res 2006; 85(1): 22-32.

[24] Sorsa T, Tjaderhane L, Salo T. Matrix metalloproteinases (MMPs) in oral diseases. Oral Dis 2004; 10(6): 311-8.

[25] Hannas AR, Pereira JC, Granjeiro JM, Tjäderhane L. The role of matrix metalloproteinases in the oral environment. Acta Odontol Scandinavia 2007; 65(1): 1-13.

[26] Kato MT, Leite AL, Hannas AR, Buzalef MAR. Gels containing MMP inhibitors prevent dental erosion in situ. J Dental Res 2010; 89(5): 468-72.

[27] Sang Q-XA, Jin Y, Newcomer RG, et al. Matrix metalloproteinase inhibitors as prospective agents for the prevention and treatment of cardiovascular and neoplastic diseases. Curr Top Med Chem 2006; 6: $289-316$.

[28] Southward K. The systemic theory of dental caries. Gen Dent 2011; 59(5): 367-73.

[29] Hurlbutt M, Novy B, Young D. Dental Caries: a pH-mediated disease. CDHA J 2010; 25(1): 9-15.

Received: November 03, 2014
(C) Low et al.; Licensee Bentham Open.

This is an open access article licensed under the terms of the Creative Commons Attribution Non-Commercial License (http://creativecommons.org/licenses/by-nc/3.0/) which permits unrestricted, non-commercial use, distribution and reproduction in any medium, provided the work is properly cited. 